\title{
Relationship of parental characteristics and feeding practices to overweight in infants and young children in Beijing, China
}

\author{
Jiang Jingxiong ${ }^{1,2, *}$, Urban Rosenqvist ${ }^{2}$, Wang Huishan ${ }^{1}$, Bert Koletzko ${ }^{3}$, \\ Lian Guangli ${ }^{1}$, Huang Jing ${ }^{1}$ and Ted Greiner ${ }^{4}$ \\ 'Department of Child Health Care, National Center for Women's and Children's Health, Beijing 100013, \\ People's Republic of China: ${ }^{2}$ Department of Public Health and Caring Science, Uppsala University, Uppsala, \\ Sweden: ${ }^{3}$ Division of Metabolic Disease and Nutrition, Dr von Hauner Children's Hospital, University of Munich, \\ Munich, Germany: ${ }^{4}$ Program for Appropriate Technology in Health (PATH), Washington, DC, USA
}

Submitted 9 January 2008: Accepted 7 July 2008: First published online 15 August 2008

\begin{abstract}
Background: Childhood obesity has become a major public health problem in many countries. To explore the risk factors of overweight in infants and young children might be helpful in developing an early overweight intervention strategy. Objective: To assess the prevalence of overweight and the relationship of parental characteristics and feeding practices to overweight in infants and young children in Beijing, China.

Design: Data on weight and length/height were collected on 4654 children aged 1-35 months in twelve communities in Beijing from a cross-sectional study. Overweight was defined as weight-for-length/height $\geq 2 \mathrm{sD}$ above the median of the WHO reference. Two hundred and fifteen families with overweight children and 215 families with normal-weight children were interviewed using a questionnaire to obtain feeding practices.

Results: The overall prevalence of overweight was $4 \cdot 7 \%$. Both parental overweight and low parental education were significantly higher among overweight than normal-weight children. The total energy intake was significantly higher in overweight than in normal-weight children at 12-35 months of age. Compared with normal-weight children, significantly fewer overweight children were breastfed for at least 4 months. Overweight children were also more likely to have been introduced to infant formula and semi-solid foods during the first 4 months.

Conclusion: Early prevention strategies should include feeding practices identified as putting children at risk of obesity. These include early cessation of breast-feeding and premature introduction of other foods.
\end{abstract}

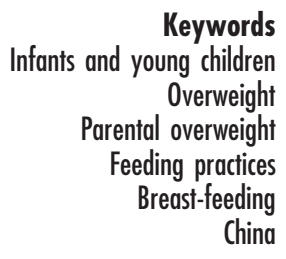

Childhood obesity has become a major public health problem in many developed and developing countries ${ }^{(1,2)}$. China has joined the world epidemic of obesity, with a high prevalence of overweight being reported among urban children ${ }^{(3)}$. It was recently estimated that about 14 million Chinese children are overweight and 6 million are obese ${ }^{(4)}$. Childhood obesity increases the risk for obesity in adulthood ${ }^{(5,6)}$ and is associated with an increased risk of later $\mathrm{CVD}^{(6)}$. Because obesity is difficult to treat, the more effective strategy is to develop healthy eating habits in early childhood that will help prevent overweight. Healthy eating patterns initiated early in life may have immediate nutritional benefits, as well as reducing the risk of later obesity.

Obesity is a multi-factorial condition influenced by both genetic and environmental factors. Parental obesity, especially maternal obesity, has been identified as a risk factor for obesity in children ${ }^{(7,8)}$. For infants and young children, parental feeding style and the foods fed are thought to influence the child's weight and to be an important factor affecting later eating habits ${ }^{(9)}$. While parental prompts, encouragement to eat and offering of food have been related to weight in young children, more research is needed on parental feeding styles and overweight in infants and young children, particularly in identifying effective approaches towards the prevention of childhood obesity.

The cultural structure in China is quite different from that in Westernized countries and it is possible that additional culture-bound risk factors play a role in the development of overweight and obesity. With the implementation of the 'family planning policy' in China since the beginning of 1980s, the single child tends to be over-cared for and often overfed by adult caregivers. More knowledge is needed on parental feeding factors influencing children's overweight and obesity in China in 
order to develop effective, culturally sensitive, early obesity prevention approaches. The purpose of the present research was to assess the prevalence of overweight in infants and young children in two Beijing districts and to explore its relationship with parental overweight and child feeding practices.

\section{Methods}

\section{Study population and sampling strategy}

There are six urban districts in Beijing, China, with ten to fifteen communities in each district. There is one community health centre responsible for the health care of children 0-3 years old in each community. Every child is issued a child health record by the community health centre when the child is born. The child's birth weight and growth data are recorded in the health record. Two urban districts were randomly selected in Beijing. Six communities were selected randomly in each district. Information describing the study was sent to all parents with children aged 1-35 months in the twelve communities.

Anthropometric measurements were taken to screen for overweight from June to August 2005 among all the children aged 1-35 months who visited any of the twelve participating community health centres. To study the determinants of young child overweight, a sub-sample was created. Parents of all 219 overweight children were invited to be interviewed, and 215 accepted and gave informed consent.

After screening, normal-weight children were matched at a ratio of 1:1 with overweight children. Normal-weight children in the same community were chosen randomly and matched with the overweight children on gender and age (age difference less than 1 month at 1-5 months of age, less than 2 months at 6-11 months of age, less than 3 months at 12-23 months of age and less than 6 months at 24-35 months of age). Seven parents with matched normal-weight children refused to be interviewed. They were replaced with seven other children from the same communities according to the rule above.

\section{Measurements}

Length (for children aged 1-24 months), height (for children aged 25-35 months) and weight were measured without shoes in light clothing by two trained community health workers in each of the twelve participating community health centres. Each measurement was performed twice and the average was used in the analysis. The same types of instruments for weight and length/height measurement were used in each of the twelve communities. Length was measured to the nearest $0 \cdot 1 \mathrm{~cm}$ with the WB-A Length Meter (Jinhe Medical Instrument Factor, Hebei, China). Height was measured to the nearest $0 \cdot 1 \mathrm{~cm}$ with the SZG-180 stadiometer (Shanghai Zhengda Weigher Company, Shanghai, China). Weight was measured to the nearest $0 \cdot 1 \mathrm{~kg}$ with the lever scale RGT-60 (Beijing Post
Institute, Beijing, China). Overweight was defined as weight-for-length/height $\geq 2 \mathrm{sD}$ above the median of the WHO reference for $\operatorname{sex}^{(10)}$, i.e. weight-for-length/height $Z$ score $\geq 2$. The birth weight data for all sample children was obtained from their child health records.

\section{Interview}

A questionnaire was administered to the parents of overweight and matched normal-weight children to obtain parental educational level, family income and feeding practices, including a $24 \mathrm{~h}$ dietary recall. After completing an initial training course, each of the twentyfour participating community health workers interviewed five individuals before they interviewed sample parents.

In all households, the primary respondent was the mother of the selected child or the principal caregiver. Parental overweight was defined as $\mathrm{BMI} \geq 24 \mathrm{~kg} / \mathrm{m}^{2}$ as per the Chinese reference for adults ${ }^{(11)}$. The mothers or caregivers of children aged 12-35 months were asked for details of the types and amounts of food consumed by their children in the past $24 \mathrm{~h}$ (backwards from when the interview was taking place to the same time the day before). The breast-feeding frequency was recorded by time of day and each feed was assumed to provide $150 \mathrm{ml}$. The Chinese food composition tables were used to calculate children's energy intakes relative to the Chinese Dietary Reference Intakes (DRI) by age and sex ${ }^{(12)}$. The trained paediatrician in the study team used a nutrition calculator (made by the Chinese National Institute of Nutrition) for intake calculation. Energy intake is reported in kilojoules and percentage of the DRI.

The study was approved by the Ethics Committee of the Chinese National Center for Women's and Children's Health before it was implemented.

\section{Statistical analysis}

The significance level was set at $P=0 \cdot 05$. Differences in the prevalence of overweight between age groups and gender were examined using the $\chi^{2}$ test. Variables with significant $(P<0.05)$ associations with children's overweight in bivariate analyses (using Fisher's exact test for categorical variables and the independent $t$ test for continuous variables) were analysed in a logistic regression model adjusting for birth weight, sex, age and family income. Clustering was controlled for, with communities as respective clusters. Odds ratios and 95\% confidence intervals were calculated for each factor. Variables are reported as means with their standard deviations or percentages.

\section{Results}

\section{Prevalence of overweight in children}

Weight and length/height were measured in 4654 children aged 1-35 months. Among them, there were 2426 boys $(52 \cdot 1 \%)$ and 2228 girls $(47 \cdot 9 \%), 1 \cdot 5 \%$ had low birth 
weight $(<2500 \mathrm{~g})$. The overall prevalence of overweight was $4.7 \%$. As shown in Table 1 , the prevalence of overweight was generally higher in boys than in girls.

\section{Parental characteristics and overweight in children}

The questionnaire survey was completed for 430 children (215 overweight children and 215 normal-weight children) aged 1-35 months. The children's BMI was significantly associated with parental BMI. The correlation coefficient was $0 \cdot 13(P=0 \cdot 01)$ for children $v$. fathers and $0 \cdot 21(P<0 \cdot 001)$ for children $v$. mothers. Both parental overweight and low parental education were also associated with overweight among children (Table 2).

\section{Food intake and infant feeding practices in overweight and normal-weight children}

There were 290 children aged 12-35 months (145 overweight and 145 normal-weight children) in the sub-sample.

Table 1 Prevalence (\%) of overweight in infants and young children from twelve communities in two urban districts of Beijing, China, 2005

\begin{tabular}{lcccc}
\hline Age (months) & Both genders & Boys & Girls & $P$ value \\
\hline $1-11(n 1446)$ & $4 \cdot 9$ & $6 \cdot 3$ & $3 \cdot 2$ & 0.007 \\
$12-23(n 1849)$ & $4 \cdot 8$ & $5 \cdot 8$ & $3 \cdot 8$ & 0.049 \\
$24-35(n$ 1359) & $4 \cdot 3$ & $5 \cdot 3$ & $3 \cdot 1$ & 0.059 \\
$1-35(n$ 4654) & $4 \cdot 7$ & $5 \cdot 8$ & $3 \cdot 4$ & 0.001 \\
\hline
\end{tabular}

*Significance of the difference between boys and girls by the $\chi^{2}$ test.
The total energy intake was significantly higher in overweight children than in normal-weight children according to the $24 \mathrm{~h}$ recall. Compared with normal-weight children, significantly fewer overweight children were breast-fed for at least 4 months. Overweight children were more likely to have been given infant formula during the first 4 months, and to have been introduced to semi-solid foods before 4 months of age (Table 3 ). Western fast food had ever been consumed by $50 \cdot 6 \%$ of children aged 12-23 months and $77 \cdot 2 \%$ by $24-35$ months, but this was not associated with overweight.

\section{Maternal feeding styles in overweight and normal-weight mothers}

There were 107 overweight mothers and 323 normalweight mothers among the families which were interviewed. Compared with normal-weight mothers, more overweight mothers worried that their children would overeat and become obese. More overweight mothers controlled feeling with a regular schedule than did normalweight mothers. The overweight mothers reported using food to soothe their children less often than normal-weight mothers (Table 4).

\section{Discussion}

The results of the present study showed that the prevalence of overweight was $4.7 \%$ in children aged 1-35 months in two districts of urban Beijing, China. This is

Table 2 Parental overweight and education levels in overweight and normal-weight children aged 1-35 months from twelve communities in two urban districts of Beijing, China, 2005

\begin{tabular}{|c|c|c|c|c|c|}
\hline & Overweight children & Normal-weight children & Adjusted OR* & $95 \% \mathrm{Cl}$ & $P$ value \\
\hline Maternal overweight (\%) & $35 \cdot 0$ & $18 \cdot 1$ & $2 \cdot 27$ & $1 \cdot 17,4 \cdot 39$ & 0.015 \\
\hline Parental overweightt (\%) & $21 \cdot 4$ & $9 \cdot 0$ & $2 \cdot 67$ & $1 \cdot 43,4.98$ & 0.002 \\
\hline Low educational level of fatherł (\%) & $39 \cdot 5$ & $27 \cdot 0$ & $1 \cdot 62$ & $1 \cdot 01,2 \cdot 67$ & 0.015 \\
\hline Low educational level of motherł (\%) & $43 \cdot 7$ & $30 \cdot 2$ & $1 \cdot 86$ & $1 \cdot 14,2 \cdot 78$ & 0.006 \\
\hline
\end{tabular}

*Adjusted for children's birth weight, age, gender, family income and community in logistic regression analysis.

tBoth parents overweight.

$\ddagger$ Middle school or uncompleted.

Table 3 Food intake and feeding practices in overweight and normal-weight children aged 12-35 months from twelve communities in two urban districts of Beijing, China, 2005

\begin{tabular}{|c|c|c|c|c|c|c|c|}
\hline \multirow[b]{2}{*}{ Variable } & \multicolumn{2}{|c|}{$\begin{array}{l}\text { Overweight children } \\
\qquad(n 145)\end{array}$} & \multicolumn{2}{|c|}{$\begin{array}{l}\text { Normal-weight children } \\
(n \text { 145) }\end{array}$} & \multirow[b]{2}{*}{ Adjusted OR* } & \multirow[b]{2}{*}{$95 \% \mathrm{Cl}$} & \multirow[b]{2}{*}{$P$ value } \\
\hline & Mean & SD & Mean & SD & & & \\
\hline Age (months) & $23 \cdot 3$ & $6 \cdot 9$ & $24 \cdot 1$ & $6 \cdot 8$ & & & 0.401 \\
\hline Energy intake (kJ) & $5210 \cdot 4$ & $1415 \cdot 3$ & $4545 \cdot 2$ & $1484 \cdot 8$ & $1 \cdot 29$ & $1 \cdot 05,2 \cdot 98$ & 0.023 \\
\hline \multirow[t]{2}{*}{$\%$ of DRI } & $110 \cdot 1$ & $30 \cdot 4$ & $96 \cdot 0$ & $31 \cdot 8$ & $1 \cdot 37$ & $1 \cdot 10,3 \cdot 05$ & 0.015 \\
\hline & \multicolumn{2}{|c|}{$\%$} & \multicolumn{2}{|c|}{$\%$} & & & \\
\hline Exclusive breast-feeding in first 4 months & \multicolumn{2}{|c|}{$52 \cdot 4$} & \multicolumn{2}{|c|}{$69 \cdot 7$} & 0.47 & $0.25,0.87$ & 0.020 \\
\hline Formula feeding in first 4 months & \multicolumn{2}{|c|}{$19 \cdot 3$} & \multicolumn{2}{|c|}{$5 \cdot 5$} & 1.45 & $1 \cdot 10,3 \cdot 28$ & 0.011 \\
\hline Introduced to semi-solids before 4 months of age & \multicolumn{2}{|c|}{$17 \cdot 9$} & \multicolumn{2}{|c|}{$11 \cdot 7$} & $1 \cdot 76$ & $1 \cdot 15,3.64$ & 0.006 \\
\hline
\end{tabular}

DRI, Dietary Reference Intake.

${ }^{\star}$ Adjusted for children's birth weight, age, gender, family income and community in logistic regression analysis. 
Table 4 Maternal feeding style in overweight and normal-weight mothers from twelve communities in two urban districts of Beijing, China, 2005

\begin{tabular}{|c|c|c|c|c|c|}
\hline \multirow[b]{2}{*}{ Variable } & \multicolumn{2}{|c|}{ Maternal overweight } & \multirow[b]{2}{*}{ Adjusted $\mathrm{OR}^{*}$} & \multirow[b]{2}{*}{$95 \% \mathrm{Cl}$} & \multirow[b]{2}{*}{$P$ value } \\
\hline & Yes & No & & & \\
\hline Child overweight (\%) & $62 \cdot 6$ & $45 \cdot 8$ & $2 \cdot 44$ & $1 \cdot 51,3.96$ & 0.001 \\
\hline Always worried that child would be obese (\%) & $55 \cdot 1$ & $35 \cdot 0$ & $2 \cdot 02$ & $1 \cdot 43,3 \cdot 84$ & 0.003 \\
\hline Always worried that child ate too much (\%) & $35 \cdot 5$ & $21 \cdot 1$ & $1 \cdot 83$ & $1 \cdot 21,2 \cdot 75$ & 0.004 \\
\hline Always fed with a regular schedule (\%) & $47 \cdot 7$ & $35 \cdot 3$ & $1 \cdot 91$ & $1 \cdot 02,4 \cdot 80$ & 0.017 \\
\hline Soothed child with food often (\%) & $8 \cdot 4$ & $20 \cdot 7$ & 0.55 & $0.28,0.89$ & 0.008 \\
\hline
\end{tabular}

${ }^{\star}$ Adjusted for children's birth weight, age, gender, BMI, maternal education level and family income.

similar to some industrialized countries and many developing countries ${ }^{(13)}$. Weight-for-length/height was used for defining overweight in the present study. Stunting (length/height-for-age $\leq 2 \mathrm{sD}$ ) can be a factor influencing this type of calculation, but the prevalence of overweight did not change when the children with stunting were excluded from the analysis. Previous research found a higher prevalence of overweight and obesity in boys than in girls in China ${ }^{(3,14)}$. This difference was also observed in the present study. Once obesity is established, therapeutic interventions are expensive and tend to have poor long-term results ${ }^{(15)}$. Thus, it is important to highlight the problem as early as possible in childhood. However, few studies have dealt with overweight in infants and young children.

Parental obesity may increase the risk of overweight through genetic mechanisms or by shared familial behavioural characteristics such as food preferences and various lifestyle factors ${ }^{(16)}$. For young children, the parents may play an even more important role since they have more control over their children's food intake compared with older children. Families with maternal overweight and both parents overweight had higher prevalence of child overweight in the present study. Children with both the mother and father overweight had a higher risk of overweight than those with only the mother overweight in logistic regression analysis. Since parental overweight is a risk factor for child overweight, this suggests a population to target for the early prevention of childhood obesity.

Other studies have also found that children of less well educated mothers are more likely to be overweight than children of more highly educated mothers ${ }^{(17)}$. In the present study, a low education level for either the father or mother was independently associated with children's overweight. Thus the parents' dietary habits and knowledge, their beliefs about and attitudes towards healthy nutrition may have an influence in developing the eating habits of young children in Chinese families. This suggests another basis for targeting health promotion.

An imbalance of energy intake and expenditure is the main cause of overweight and obesity ${ }^{(18)}$. The results of $24 \mathrm{~h}$ recalls showed that energy intake in overweight children was above the DRI and was significantly higher than in normal-weight children. Young children have less physical activity compared with older children. Thus energy intake alone may be the most important factor causing overweight among young children. Our study documented a significantly lower rate of exclusive breastfeeding during the first 4 months in overweight children than in normal-weight children. Early formula feeding and introduction of semi-solid food (before 4 months of age) were also significantly more common among overweight than normal-weight children. These findings are consistent with those of several previous studies ${ }^{(19,20)}$. Early feeding is a crucial determinant of childhood obesity. Overweight children were less accurate in energy intake regulation $^{(21)}$. Breast-feeding may protect or help develop the infant's ability to sense internal cues for hunger and satiety. Formula feeding always involves more parental control, likely to interfere with infant self-regulation of energy intake ${ }^{(22)}$. Breast-feeding has been demonstrated to prevent childhood obesity in some studies ${ }^{(23,24)}$. It was also a protective factor against overweight in the present study. Optimal infant feeding practices, including exclusive breast-feeding through the first 6 months, may minimize early overweight.

Mothers are usually the primary caregivers for young children and take the main responsibility for children's food intake ${ }^{(25)}$. Parental feeding practices are the main factor influencing young children's diets. Other possible aspects of the family environment, such as time spent watching television and other media and physical activity patterns, may have a less direct influence on children's food intake in early childhood than for older children. Our study showed that overweight mothers were more concerned about their children's overeating or becoming obese than normal-weight mothers. Compared with normalweight mothers, more overweight mothers reported that they controlled child feeling with a regular schedule and less often soothed children with food. Other studies have also found that overweight mothers have a heightened concern for their children's weight status ${ }^{(26,27)}$. They fear that later in life their children will be subjected to struggles with weight and eating similar to their own. This heightened parental awareness may often protect children against parental behaviours that could lead to a later increase in adiposity ${ }^{(28)}$. Indulgent child-feeding practices and lack of parental awareness about the health 
risks of childhood obesity have been documented to be associated with childhood obesity ${ }^{(29)}$. However, it seems that such worries may not completely solve the problem in our study. We found a significantly higher prevalence of child overweight in the maternal overweight group than among normal-weight mothers. Similar to other studies $^{(27,30)}$, maternal BMI was significantly correlated with children's BMI. A possible interpretation might be that mothers' cognitive approaches worked poorly to influence children's diets. In China, we suggested earlier that other caregivers, particularly grandparents, may often have the main responsibility for child feeding, and they tend to be positive towards overweight in children ${ }^{(31)}$. However, further prospective research in the Chinese setting is needed to determine if high parental concern about children becoming overweight may be detrimental to preventing overweight among infants and young children who are still developing eating habits.

Although the districts and communities included in our sample were selected randomly and anthropometric data were available for $98 \%$ of the eligible population, there might be sampling bias to influence our results. Since food consumption was assessed using a $24 \mathrm{~h}$ recall, misreporting might have occurred. Despite its limitations, the present study has made an important start in investigating overweight in infants and young children in the Beijing area of China.

The present study found that the prevalence of overweight was high in infants and young children in urban areas of Beijing. Parental overweight, low parental education level, formula feeding during the first 4 months of age, early introduction of semi-solid foods and high energy intake were each independently related to child overweight. Overweight mothers had a higher concern about their children overeating and becoming obese. Existing evidence suggests that effective early childhood interventions can shift the balance from risk to protective factors. Prevention of childhood obesity should give substantial attention to improving child feeding practices, especially achieving exclusive breast-feeding for 6 months. Education about scientific feeding should be targeted first to overweight parents and those with low education level. Future research should include prospective studies on child feeding in an effort to identify effective preventive strategies to prevent early childhood obesity.

\section{Acknowledgements}

The work was carried out in the National Center for Women's and Children's Health, Beijing, China. Each of the authors declares that he or she has no conflict of interest regarding this study. The study was supported with a research grant from Dumex Sciences. We thank all the parents, children and health-care doctors who took part in the study for their commitment. We thank Dr Song Qinsu, Dr Liu Yan and Dr Wu Yunmei for helping to arrange the field work and Professor Ding Zongyi for his advice on the study design. Author contributions: J.J., research and writing; U.R., writing; W.H., research; B.K., writing; L.G., research; H.J., writing; T.G., writing.

\section{References}

1. Dehghan M, Akhtar-Danesh N \& Merchant AT (2005) Childhood obesity, prevalence and prevention. Nutr J 4, 24 .

2. Ebbeling CB, Pawlak DB \& Ludwig DS (2002) Childhood obesity: public-health crisis, common sense cure. Lancet 360, 473-482.

3. Iwata F, Hara M, Okada T, Harada K \& Li S (2003) Body fat ratios in urban Chinese children. Pediatr Int 45, 190-192.

4. Wu YF (2006) Overweight and obesity in China. BMJ 333, 362-363.

5. Whitaker RC, Wright JA, Pepe MS, Seidel KD \& Dietz WH (1997) Predicting obesity in young adulthood from childhood and parental obesity. N Engl J Med 337, 869-873.

6. Freedman D (2002) Clustering of coronary heart disease risk factors among obese children. J Pediatr Endocrinol Metab 15, 1099-1108.

7. Jiang JX, Rosenqvist U, Wang HS, Greiner T, Ma Y \& Toschke AM (2006) Risk factors for overweight in 2- to 6 -y-old children in Beijing, China. Int J Pediatr Obes 1, 103-108.

8. Toschke AM, Beyerlein A \& von Kries R (2005) Children at high risk for overweight: a classification and regression trees analysis approach. Obes Res 13, 1270-1274.

9. Wardle J, Sanderson S, Guthrie CA, Rapoport L \& Plomin R (2002) Parental feeding style and the inter-generational transmission of obesity risk. Obes Res 10, 453-462.

10. de Onis M, Garza C, Onyango AW \& Martorell R (2006) WHO child growth standards. Acta Paediatr 95, S76-S85.

11. Chinese Task Force of Obesity (2004) [The reference of overweight and obesity for Chinese children]. Chin J Epidemiol 25, 97-102.

12. Chinese Nutrition Society (2001) [Chinese Dietary Reference Intakes]. Beijing: China Light Industry Press.

13. de Onis M (2004) The use of anthropometry in the prevention of childhood overweight and obesity. Int $J$ Obes Relat Metab Disord 28, S81-S85.

14. Ding ZY, He Q, Fan ZH et al. (1998) [National epidemiological study on obesity of children aged $0-7$ years in China 1996]. Natl Med J China 78, 121-123.

15. Barlow SE \& Dietz WH (1998) Obesity evaluation and treatment: Expert Committee recommendations. The Maternal and Child Health Bureau, Health Resources and Services. Administration and the Department of Health and Human Services. Pediatrics 102, E29.

16. Francis LA, Lee Y \& Birch LL (2003) Parental weight status and girls' television viewing, snacking, and body mass indexes. Obes Res 11, 143-151.

17. Chen JL \& Kennedy C (2005) Factors associated with obesity in Chinese-American children. Pediatr Nurs 31, $110-115$

18. Schmitz MKH \& Jeffery RW (2000) Public health interventions for the prevention and treatment of obesity. Med Clin North Am 84, 491-512.

19. von Kries R, Koletzko B, Sauerwald T, von Mutius E, Barnert D, Grunert V \& von Voss H (1999) Breast feeding and obesity: cross sectional study. BMJ 319, 147-150.

20. Burdette HL, Whitaker RC, Hall WC \& Daniels SR (2006) Breastfeeding, introduction of complementary foods, and adiposity at 5 y of age. Am J Clin Nutr 83, 550-558.

21. Johnson SL (2000) Improving preschoolers' self-regulation of energy intake. Pediatrics 106, 1429-1435. 
22. Hodges EA (2003) A primer on early childhood obesity and prenatal influence. Pediatr Nurs 29, 13-16.

23. Grummer-Strawn LM \& Mei Z; Centers for Disease Control and Prevention Pediatric Nutrition Surveillance System (2004) Does breastfeeding protect against pediatric overweight? Analysis of longitudinal data from the Centers for Disease Control and Prevention Pediatric Nutrition Surveillance System. Pediatrics 113, e81-e86.

24. von Kries R, Koletzko B, Sauerwald T \& von Mutius E (2000) Does breast-feeding protect against childhood obesity? Adv Exp Med Biol 478, 29-39.

25. Bramhagen AC, Axelsson I \& Hallstrom I (2006) Mothers' experiences of feeding situations - an interview study. J Clin Nurs 15, 29-34.

26. Birch LL \& Fisher JO (2000) Mothers' child-feeding practices influence daughters' eating and weight. $A m ~ J$ Clin Nutr 71, 1054-1061.
27. Burdette HL, Whitaker RC, Hall WC \& Daniels SR (2006) Maternal infant-feeding style and children's adiposity at 5 years of age. Arch Pediatr Adolesc Med 160, 513-520

28. Spruijt-Metz D, Li C, Cohen E, Birch L \& Goran M (2006) Longitudinal influence of mothers' child-feeding practices on adiposity in children. I Pediatr 148, 314-320.

29. Brewis A (2003) Biocultural aspects of obesity in young Mexican schoolchildren. Am J Hum Biol 15, 446-460.

30. Faith MS, Berkowitz RI, Stallings VA, Kerns J, Storey M \& Stunkard AJ (2004) Parental feeding attitudes and styles and child body mass index: prospective analysis of a geneenvironment interaction. Pediatrics 114, 429-436.

31. Jiang JX, Rosenqvist U, Wang HS, Greiner T, Lian GL \& Sarkadi A (2007) Influence of grandparents on eating behaviors of young children in Chinese three-generation families. Appetite 48, 377-383. 